\title{
Learning and performance evaluation in distance higher education: a case study during the Covid- 19 pandemic
}

\author{
Davide Capperucci ${ }^{1}$, and Ilaria Salvadori ${ }^{2}$ \\ ${ }^{1}$ University of Florence, Department of Education, Languages, Interculture, Literatures and \\ Psychology, 48 Via Laura, Florence, Italy \\ ${ }^{2}$ University of Florence, Department of Education, Languages, Interculture, Literatures and \\ Psychology, 48 Via Laura, Florence, Italy
}

\begin{abstract}
The Covid-19 pandemic has caused disruption in students' education and imposed numerous and unprecedented challenges on the educational systems all over the world turning the traditional learning processes into online distance education. The new context has raised the question of how to evaluate students' learning and competences in distance education environments as effectively as possible. To maintain high quality standards of higher education, it is undoubtedly necessary to investigate through which tools the lecturers evaluate both the processes and the products of learning gained in online education. This study has been carried out at the University of Florence, with a sample of 60 lecturers, during the first period of pandemic. It has a twofold aim: (1) investigating lecturers' beliefs on assessment and evaluation in distance higher education and (2) comparing online assessment techniques and tools with those used in face-toface classroom practices. The case study uses mixed methods and proposes data collected through an online questionnaire and semi-structured interviews analyzed with a quanti-qualitative approach. It pointed out the main problems the study group faced in evaluating students' learning and performance in remote university education and suggested, at the same time, possible solutions to tackle learning and performance evaluation processes through alternative assessment methods.
\end{abstract}

\section{Introduction}

The emergency imposed by the Covid-19 pandemic has had a significant impact on the education systems worldwide and has imposed new priorities. Educational disruption in March 2020 led to a radical transformation of the learning context, re-thinking and reshaping teaching and the need to find alternative approaches. Distance education has become the only feasible and effective way to address the situation, but it has implied reprioritizing curriculum goals, moving teachers and students from classrooms to online environments and platforms using technological devices and defining appropriate student's assessment mechanisms. Once distance teaching-learning protocol has been activated and implemented, other issues gained momentum approaching the end of the scholastic year, the evaluation process become cogent. The Italian government decreed 
strategies and methods of integration and recovery of learning in schools of all levels. Ensuring integrity of the assessment of students learning has been identified as one of the most critical needs to be addressed by all the nations [1]. The evaluation process has always been a complex issue to tackle because it recalls an appropriate cultural approach and during this period it become even more complicated and complex to be effective [2]. The present research starts from the following questions: how has the issue of performance evaluation and assessment in university courses been addressed during the pandemic? How did university lectures decide to structure the exams in remote education?

The paper aims to focus on the role of assessment and performance evaluation in distance higher education at the University of Florence (Italy) investigating how it has been addressed by 60 lectures during the COVID-19 pandemic, considering their beliefs on assessment and evaluation and comparing online assessment techniques and tools with those used in face-to-face classroom practices. In particular, the research intends to: (i) inquire into alternative assessment tools and techniques mostly used in distance education as a substitute for face-to-face teaching; (ii) bring out the difficulties encountered in the use of alternative assessment methods and how they were solved.

This article is organized as follows: the introduction defines the statement of the problem and provides a review on the topic. Section 2 presents the theoretical framework underlying the research focused on alternative assessment as the better formative choice in this complex scenario of distance learning that guarantee students' involvement in the learning process. Section 3 is dedicated to the survey description and the research methodology. The study has adopted a mixed-method design with a sequential explanatory model using an online validated questionnaire to collect information about the assessment tools and techniques the lectures have used in their online courses, both traditional such as oral and written examination in the form of assignments, open-ended and short answers, multiple-choice exercises, and alternative as self-assessment, peerassessment, group assessment, e-portfolios and digital concept maps. Qualitative data from semi-structured interviews protocol investigated by content analysis method allow to detect the perception of the lectures regarding alternative assessment effectiveness, the difficulties envisaged and suggestions to cope with distance education evaluation. Obstacles for implementing alternative assessment refer to the difficult integration of the different assessment forms, the time-consuming method, the difficulty in proposing authentic tasks and in using communication and technology tools online. Research results show that while acknowledging the benefits of alternative forms of assessment, the tendency of professors is to turn to classic assessment tools usually used in presence in distance education since they provide greater security in such a complex period. Furthermore, while claiming to prefer recent assessment techniques and student-centered modalities, the questionnaire data show that more than half of the sample do not use or only partially use these modalities.

Discussion on the collected data and results obtained are proposed in section 4 where a re-thinking of the traditional assessment and evaluation process is proposed suggesting integrating traditional and alternative assessment methods and calling for further research evidence on the field to increase the effectiveness of alternative assessment tools and techniques in terms of validity and reliability.

\section{Theoretical framework: the need for alternative assessment}

Learning assessment is a fundamental feedback mechanism in education that enables understanding what is being learned and where implementing is needed to achieve the expected learning goals. The evaluation carried out by teachers can take different ways 
depending on its purpose: it can take place at the beginning of the educational process and have a diagnostic function, it can take place at the end to evaluate what has been done, generally in numerical terms and have summative function, and it can take place during the process assuming a formative value. Coined by Scriven, the term "formative evaluation" refers to a type of evaluation that occurs during the learning process to detect weaknesses and to advance teaching and learning processes accordingly [3-4]. It has also been applied in online education context in the form of e-assessment [5-6].

Before the pandemic, learning assessment modalities were carried out in physical presence of students using traditional written exams such as standardized tests, multiple choices questionnaire, closed questions, or oral exams. Schools and universities closure has resulted in unexpected change in education delivery and has implied the development of alternative approaches for feedback information. Alternative assessment has been considered the best way to realize the formative aims of the evaluation process [7].

From the 1990s, alternative assessment emerged as a method to gauge students learning differently from traditional forms of assessment in the classrooms, especially formal testing, promoting active students' participation, students' awareness of the assessment process and of the criteria adopted and self-assessment process [8-9]. The method appears to be rooted in the constructivist view of learning and in vygotskyian socio-cultural approach: implementing alternative assessment methods results in a new role for learners as constructor of knowledge, using authentic materials and activities and ongoing evaluation tools to empower the students [10-11]. Enabling students to perform authentic activities in real-life situations results in positive effects on students' academic achievement [12]. "The point of alternative assessments [....] is not that they are ends in themselves but that they are designed to foster powerful, productive learning for students» [13].

Alternative assessment means that students have a choice regarding the form and content they provide to offer proof to the educator that effective learning did occur. Alternative assessment is an umbrella term that can include various and wide-ranging options. It should enable students to move beyond curriculum-bounded knowledge retention and skill acquirements towards building capacity and capability [14]. Alternative assessment uses activities that reveal what students are able to do with the knowledge and skills obtained through learning, emphasising their abilities and strengths, instead of focussing on their weaknesses and what they do not know. Even failure can be seen as a valuable component of the learning process and not as an outcome [15]. The process of building meaning through personal responsibility and choices gives students the freedom to explore ideas, to raise questions and objections or to construct meaning in a "community of inquiry" where students can use alternative assessment tasks to develop attitudes and skills to become critical thinkers and to continue their learning beyond the narrow scope and time limit of a formal educational experience [16].

The research has highlighted that traditional forms of assessment tests have been mostly used even if the widespread perception of lectures is that of resorting to alternative forms of assessment that guarantee the quality of teaching-learning processes. The need for alternative forms of assessment has emerged for which, however, an adequate training of teachers is required also about the technological aspects from the pedagogical perspective (the TPK framework) [17]. 


\section{Assessment and evaluation methods in distance higher education: an in-field research on alternative assessment}

\subsection{Survey description}

The present research aimed to investigate the role of assessment and evaluation in distance higher education of university programs during the Covid-19 pandemic. The research was carried out from March 2019 to February 2021, when, cause the pandemic, both the courses and the exams of the University of Florence were carried out remotely. Previously, all courses and exams were held in presence. The present survey intended to investigate which assessment and evaluation tools and techniques were mostly used by lecturers during the emergency period, what difficulties they encountered in the use of distance alternative assessment methods and how they tried to overcome them.

The study was carried out with 60 lecturers of the School of Humanities and Education of the University of Florence. The demographic characteristics of lecturers are reported in Table 1.

Table 1. Demographic information of lecturers.

\begin{tabular}{|l|l|c|c|}
\hline \multicolumn{1}{|c|}{ Variable } & \multicolumn{1}{|c|}{ Group } & N & \% \\
\hline \multirow{3}{*}{ Gender } & Female & 32 & 53.3 \\
\cline { 2 - 4 } & Male & 28 & 46.7 \\
\hline Total & & 60 & 100 \\
\hline \multirow{4}{*}{$\begin{array}{l}\text { Professional } \\
\text { experience }\end{array}$} & 0-5 Years & 19 & 31.7 \\
\cline { 2 - 4 } & 6-10 Years & 13 & 21.6 \\
\cline { 2 - 4 } & 11-15 Years & 15 & 25.0 \\
\cline { 2 - 4 } & 16-20 Years & 9 & 15.0 \\
\cline { 2 - 4 } & 21 Years and more & 4 & 6.7 \\
\hline Total & & 60 & 100 \\
\hline \multirow{3}{*}{$\begin{array}{l}\text { Number of courses } \\
\text { delivered in distance } \\
\text { education per lecturers }\end{array}$} & 1 Course & 20 & 33.3 \\
\cline { 2 - 4 } & 2 Courses & 15 & 25.0 \\
\cline { 2 - 4 } & 3 Courses & 12 & 20.0 \\
\cline { 2 - 4 } & 4 Courses & 6 & 10.0 \\
\cline { 2 - 4 } & 5 Courses and more & 7 & 11.7 \\
\hline Total & & 60 & 100 \\
\hline
\end{tabular}

The research model of the present study was based on a mixed methods design [18], with the integration of qualitative and quantitative research methods through a sequential explanatory design [19]. The quantitative data was collected using an online questionnaire taken from international literature and validated in previous research on distance learning in higher education [20]; the qualitative data was collected through semi-structured interviews carried out by the research group.

The questionnaire was made of two parts. The first part included questions on demographic information of the participants. The second part provided questions on the assessment tools and techniques that lecturers used in distance education, including also those that docimological research considers alternative [21-22].

In semi-structured interview some central aspects, already emerged from the replies to the questionnaire and treated in the international literature on alternative assessment methods [23], were investigated. At this phase of the research, lecturers were asked questions towards determining the reasons related to their evaluation choices, to what extent and why they had chosen alternative assessment and evaluation methods in 
distance education, what restrictions and problems in using alternative assessment and evaluation methods they encountered, especially in evaluating student success and performance proficiency, and finally what solutions towards solving these problems were experimented. Content analysis method was used in analysing the qualitative data collected through semi-structured interviews. The data emerged from this research section was examined in detail by the researchers using the Atlas software [24], which made it possible to develop a coding system for the information collected and to detect specific analytical functions. The data were coded by two researchers with the coding reliability percentage found at $89 \%$. The data corresponding to the remaining $11 \%$ was discussed with a panel of 5 other researchers who knew the purposes and structure of the research but who were not directly involved in the interviews.

Table 2 summarizes the absolute and percentage data of the assessment and evaluation tools used by lecturers in assessing students' learning and performance online.

Table 2. Assessment and evaluation tools and techniques chosen by lecturers.

\begin{tabular}{|c|c|c|c|c|c|c|c|c|c|c|}
\hline \multirow{2}{*}{$\begin{array}{l}\text { Assessment and } \\
\text { evaluation tools/ } \\
\text { techniques used by } \\
\text { lecturers in online } \\
\text { education }\end{array}$} & \multicolumn{2}{|c|}{ Always } & \multicolumn{2}{|c|}{ Generally } & \multicolumn{2}{|c|}{ Sometimes } & \multicolumn{2}{|c|}{ Rarely } & \multicolumn{2}{|c|}{ Never } \\
\hline & f & $\%$ & f & $\%$ & f & $\%$ & f & $\%$ & f & $\%$ \\
\hline Online oral examinations & 2 & 3.3 & 7 & 11.7 & 8 & 13.3 & 7 & 11.7 & 36 & 60.0 \\
\hline $\begin{array}{l}\text { Online written (open-ended) } \\
\text { examinations }\end{array}$ & 16 & 26.6 & 18 & 30.0 & 10 & 16.7 & 7 & 11.7 & 9 & 15.0 \\
\hline $\begin{array}{l}\text { Online multiple-choice } \\
\text { examinations }\end{array}$ & 15 & 25.0 & 19 & 31.6 & 10 & 16.7 & 4 & 6.7 & 12 & 20.0 \\
\hline $\begin{array}{l}\text { Online true-false } \\
\text { examinations }\end{array}$ & 8 & 13.3 & 14 & 23.4 & 11 & 18.3 & 9 & 15.0 & 18 & 30.0 \\
\hline $\begin{array}{l}\text { Online short-answer } \\
\text { examinations }\end{array}$ & 7 & 11.7 & 18 & 30.0 & 10 & 16.7 & 6 & 10.0 & 19 & 31.6 \\
\hline E-portfolio & 6 & 10.0 & 9 & 15.0 & 9 & 15.0 & 12 & 20.0 & 24 & 40.0 \\
\hline Digital concept maps & 4 & 6.7 & 7 & 11.7 & 7 & 11.7 & 8 & 13.3 & 34 & 56.6 \\
\hline Assignments & 8 & 13.3 & 18 & 30.0 & 11 & 18.3 & 5 & 8.4 & 18 & 30.0 \\
\hline Check list & - & - & 5 & 8.4 & 12 & 20.0 & 6 & 10.0 & 37 & 61.6 \\
\hline Rubric & 3 & 5.0 & 4 & 6.7 & 15 & 25.0 & 4 & 6.7 & 34 & 56.6 \\
\hline Students' e-presentation & 7 & 11.7 & 13 & 21.6 & 16 & 26.7 & 3 & 5.0 & 21 & 35.0 \\
\hline Self-assessment & 5 & 8.4 & 7 & 11.7 & 10 & 16.7 & 4 & 6.7 & 34 & 56.5 \\
\hline Peer-assessment & 4 & 4.3 & 5 & 6.5 & 7 & 10.9 & 4 & 4.3 & 40 & 74.0 \\
\hline Group assessment & 2 & 3.3 & 2 & 3.3 & 14 & 23.4 & 5 & 8.4 & 37 & 61.6 \\
\hline
\end{tabular}

The descriptive statistics highlight a more frequent use of traditional assessment tools and techniques, linked to traditional teaching methodologies based on lectures and 
teaching transmission models rather than on authentic and laboratory approaches. As demonstrated by other research [25], even in this case study, the necessity of having to use only distance learning, because of the emergency context deriving from the pandemic, seems to have reinforced a return to consolidated assessment tools, considered valid for the evaluation of knowledge from classical docimological research but not as effective for the assessment of competences. As evidenced by the data in Table 2 and the absolute and percentage figures referred to the points "Always" and "Generally" on the scale, the choices of the lecturers focused mainly on tools such as "Online written (open-ended) examinations" ( $\mathrm{f}=16+18 ; \%=26.6+30.0)$, "Online multiple choice examinations" $(\mathrm{f}=15+19 ; \%=25.0+31.6)$, "Assignments" $(\mathrm{f}=8+18$; $\%=13.3+30.0)$, a little less frequently on "Online true-false examinations" $(\mathrm{f}=8+14$; $\%=13.3+23.4$ ) and "Online short-answer examinations" (f $=7+18 ; \%=11.7+30.0$ ). Among the less used assessment tools and techniques we find those that provide a more active, cooperative and participatory role of the students, such as "E-portfolio", "Check list", "Rubric", "Students' e-presentation", "Self-assessment", "Peerassessment", and "Group assessment".

Table 3 reports lecturers' perceptions to what extent they use the latest developments on assessment and evaluation methods, attributable to alternative evaluation.

Table 3. Descriptive statistics on lecturers' perceptions to what extent they use the latest developments on assessment and evaluation methods.

\begin{tabular}{|l|c|c|}
\hline $\begin{array}{c}\text { Choice of the latest assessment } \\
\text { and evaluation methods }\end{array}$ & f & \% \\
\hline I do not follow & 16 & 26.7 \\
\hline I partially follow & 18 & 30.0 \\
\hline I follow & 26 & 43.3 \\
\hline Total & 60 & 100 \\
\hline $\begin{array}{c}\text { Choice of student-centred assessment and } \\
\text { evaluation methods }\end{array}$ & f & \% \\
\hline I do not prefer & 5 & 8.4 \\
\hline I rarely prefer & 16 & 26.6 \\
\hline I sometimes prefer & 31 & 51.7 \\
\hline I always prefer & 8 & 13.3 \\
\hline Total & 60 & 100 \\
\hline
\end{tabular}

From the answers to the questionnaire it emerges that among the 60 lecturers participating in the survey $16(26,7 \%)$ of them declared not to follow the developments on the latest assessment and evaluation methods, whilst $18(30.0 \%)$ indicated that they partially follow these developments and $26(43,3 \%)$ of them did it habitually. This data requires to be further investigated, because it documents a different trend from that attributable to the most frequently chosen evaluation methods, that, as written in Table 2 , saw a prevalence of traditional evaluation approaches rather than more innovative ones. The perception of most of the lecturers was to use innovative assessment methods even in distance education contexts, although the quantitative data that emerge from the questionnaire highlight a partly different reality. Regarding the frequency with which student-centered assessment methods were chosen by the lecturers, it seems to provide more coherent data, in fact only 5 lecturers, corresponding to the $8.4 \%$ of the total, say they did not use alternative evaluation tools 
and techniques, $16(26.6 \%)$ used them "rarely" 31 (51.7\%) were those who used them "sometimes", and $8(13.3 \%)$ "always" From an overall analysis of the preferences expressed by the lecturers it emerges how developments in assessment and studentcentered alternative evaluation practices are rarely chosen.

From the content analysis applied to the answers of the semi-structured interview it has been possible to understand why lecturers considered alternative assessment and evaluation methods effective and what were the most frequently difficulties they faced in using them in a widespread manner. In this case for innovative and alternative assessment tools and practices were intended instruments such as the e-portfolio, digital concept maps, self-assessment, peer and group assessment techniques.

Tables 4 and 5 respectively report the views of the lecturers.

Table 4. Descriptive statistics on lecturers' perceptions of alternative assessment and evaluation techniques effectiveness in distance higher education.

\begin{tabular}{|l|c|}
\hline Sub-themes & f \\
\hline Because it makes students active and eager in the learning process & 48 \\
\hline $\begin{array}{l}\text { Because it gives clues about whether learning has been achieved } \\
\text { or about the quality of learning }\end{array}$ & 46 \\
\hline Because it contributes to students' competence development & 44 \\
\hline $\begin{array}{l}\text { Because it gives students the opportunity to show their } \\
\text { competencies and performance in situated contexts }\end{array}$ & 43 \\
\hline $\begin{array}{l}\text { Because it makes it easier to know how students activate problem } \\
\text { solving processes applied to real and authentic situations }\end{array}$ & 40 \\
\hline $\begin{array}{l}\text { Because it enables assessing students' learning and performance } \\
\text { throughout the process of education }\end{array}$ & 38 \\
\hline $\begin{array}{l}\text { Because it gives students the opportunity to communicate with each } \\
\text { other and to cooperate }\end{array}$ & 37 \\
\hline $\begin{array}{l}\text { Because it gives the opportunity to assess student development } \\
\text { from different views }\end{array}$ & 35 \\
\hline $\begin{array}{l}\text { Because it gives the opportunity to follow student achievement } \\
\text { systematically paying attention to their feedback }\end{array}$ & 34 \\
\hline $\begin{array}{l}\text { Because it shows the extent to which students are able to correct } \\
\text { themselves while carrying out a task }\end{array}$ & 33 \\
\hline Because it helps students strengthen their study method & 33 \\
\hline $\begin{array}{l}\text { Because it enables students to access more resources in the process } \\
\text { of learning }\end{array}$ & 32 \\
\hline Because it enables peer assessment & 31 \\
\hline Because it encourages students to prepare for the course & 21 \\
\hline
\end{tabular}

Table 5. Descriptive statistics on lecturers' perceptions of the difficulties associated with the use of alternative assessment tools and techniques in distance higher education

\begin{tabular}{|l|c|}
\hline Sub-themes & f \\
\hline $\begin{array}{l}\text { Because using alternative assessment and evaluation techniques } \\
\text { alone is considered insufficient }\end{array}$ & 46 \\
\hline $\begin{array}{l}\text { Because students and lecturers do not actively use the online } \\
\text { system, especially for assessment and evaluation activities }\end{array}$ & 45 \\
\hline $\begin{array}{l}\text { Because the evaluation takes a long time, and requires a lot of time } \\
\text { and effort }\end{array}$ & 45 \\
\hline $\begin{array}{l}\text { Because sometimes connectivity problems and technological } \\
\text { difficulties make it difficult to use alternative assessment and } \\
\text { evaluation techniques in distance education contexts }\end{array}$ & 42 \\
\hline
\end{tabular}




\begin{tabular}{|l|c|}
\hline $\begin{array}{l}\text { Because it is difficult to follow the realization of an authentic task } \\
\text { or a performance task in distance education contexts }\end{array}$ & 37 \\
\hline $\begin{array}{l}\text { Because lecturers need more skills and preparation in the use of } \\
\text { alternative assessment and evaluation techniques, especially if } \\
\text { applied to distance education activities }\end{array}$ & 35 \\
\hline $\begin{array}{l}\text { Because it does not provide same opportunities that face-to-face } \\
\text { communication and interaction with students does }\end{array}$ & 22 \\
\hline $\begin{array}{l}\text { Because it is difficult to determine whether the assignment was } \\
\text { made by the student or not }\end{array}$ & 21 \\
\hline Because it can not prevent cheating & 21 \\
\hline $\begin{array}{l}\text { Because it might not be convenient for cases in which instant } \\
\text { feedback is necessary }\end{array}$ & 21 \\
\hline $\begin{array}{l}\text { Because in distance education, it is difficult to control the practices } \\
\text { students carry out }\end{array}$ & 20 \\
\hline $\begin{array}{l}\text { Because it is not possible to determine to what extent students } \\
\text { understand the contents of the subject in depth }\end{array}$ & 20 \\
\hline
\end{tabular}

Tables 4 and 5 show the most significant data on the strengths and weaknesses that the sample lecturers attribute to the use of alternative evaluation tools and techniques in distance higher education. In this case, only those indicators that have been pointed out at least one third of the lecturers (20 out of 60 ) thanks to the content analysis have been considered.

As the data demonstrate, most of the lecturers have a positive perception of the effectiveness of alternative assessment methods and believe that they can be useful both in terms of the development of students' learning and competences and in raising quality of distance learning. Almost two thirds of the lecturers who participated in the semistructured interviews believe that the alternative evaluation "makes students active and eager in the learning process" (48); "gives clues about whether learning has been achieved or about the quality of learning" (46); "contributes to students' competence development" (44); "gives students the opportunity to show their competencies and performance in situated contexts" (43), "makes it easier to know how students activate problem solving processes applied to real and authentic situations" (40), "enables assessing students' learning and performance throughout the process of education" (38), "gives students the opportunity to communicate with each other and to cooperate" (37). These statements about alternative evaluation theories are corroborated by other empirical research findings [26-27].

Despite this general appreciation of alternative assessment tools and techniques, their use in distance higher education practice is not as widespread, as evidenced by the data in Table 2. This still limited use is explained by the difficulties that the lecturers express during interviews and dealing with the need to integrate forms of authentic evaluation and traditional evaluation (46); the time required for the design of authentic evaluation tools (45); the presence of technological and connectivity problems (42); the difficulty in maintaining the authenticity of the assigned tasks due to the technological medium (37); the need for more training and preparation of lecturers on the use of alternative assessment tools, even more so if applied to distance higher education (35); the prevention and management of cheating situations (21): the impossibility of directly following the phases of carrying out an authentic task and being able to provide immediate feedback (21). All these criticalities are well highlighted in Table 5. 
Faced with the critical issues reported by the lecturers during the semi-structured interviews, the researchers asked them what could be the measures to be taken to increase the effectiveness and use of alternative evaluation tools and techniques in distance higher education. Table 6 shows the proposals with a higher frequency given by the sample.

Table 6. Lecturers' suggestions on how to cope with the problems experienced in evaluating student learning and performance in distance higher education.

\begin{tabular}{|l|c|}
\hline Sub-themes & f \\
\hline $\begin{array}{l}\text { Giving students assignments and practices that will not require memorizing but will } \\
\text { enable them to use high-order thinking skills and prevent from cheating }\end{array}$ & 47 \\
\hline $\begin{array}{l}\text { Students and lecturers should be provided with trainings on assessment and } \\
\text { evaluation from time to time }\end{array}$ & 47 \\
\hline Online exam systems should be made more practical and interactive & 46 \\
\hline More project assignments should be given instead of online exams & 45 \\
\hline $\begin{array}{l}\text { Students should also make a presentation of the assignments they prepared, and this } \\
\text { should be a criteria considered in the process of evaluation }\end{array}$ & 44 \\
\hline $\begin{array}{l}\text { Assignment directions should be well-defined, and students should be given guidance } \\
\text { during the process }\end{array}$ & 42 \\
\hline Self-assessment and group assessment should be made throughout the project & 40 \\
\hline Enabling students to make inter-group assessment throughout the project & 38 \\
\hline
\end{tabular}

One of the most significant acquisitions that emerges from this last section of the semi-structured interviews is the awareness on the part of the lecturers that in the evaluation of distance learning activities, even more so in emergency contexts, the tools and methods of evaluation to be used cannot be the same as those used in contexts of normality and in presence evaluation. Therefore, if the alternative evaluation allows to value the authenticity of the competences acquired by the students, this is even more true in distance education, where the risk of erudition as an end in itself is always very high. To enhance the formative function of alternative evaluation, considered not only as the final moment of a course in which students' learning results are tested, but as an instrument that helps the construction of increasingly complex acquisitions, it is necessary to propose tasks that do not only provide answers to questions, but above all carry out projects, create artefacts, activate processes of planning, problem solving, reviewing of products/results, stimulate peer collaboration, self-evaluation and co-evaluation (Table 6) [28-29-30].

\section{Discussion and conclusion}

The data collected thanks the questionnaire and semi-structured interviews demonstrate a widespread tendency of lecturers to transpose assessment and evaluation methods typical of face-to-face teaching into distance education [31]. This tendency seems to hide the attempt to face the uncertainties deriving from the use of innovative approaches and from the pandemic itself, taking refuge in the choice of traditional evaluation tools which, in some ways, confer security and which are considered valid in each case due to a consolidated use over time. In fact, it is no coincidence that most of the lecturers' choices have been oriented towards online assessment and evaluation techniques based on online exams (open-ended, multiple choice, true-false, short-answer questions, assignments, etc.) [32]. 
In the present research, most lecturers recognize the importance of alternative assessment tools and techniques, and believe that they are particularly effective for assessing competences. Furthermore, they are functional to stimulate the participation and direct involvement of students in online educational activities, increasing students' motivation to study, their meta-reflective, reasoning, problem solving and teamwork abilities through evaluation. The lecturers also recognize that the authentic nature that characterizes alternative evaluation makes it a fundamental tool for the assessment of performance-based learning outcomes, which goes far beyond the simple acquisition of abstract information and knowledge [33]. In many cases, alternative evaluation, proposing authentic tasks related to real and situated situations, requires students to act not as passive learners but as researchers, placing students at the centre of the distance education and assessment processes. Analysing lecturers' opinions on alternative assessment and evaluation techniques, they affirm to follow the latest developments in assessment and evaluation and that they prefer to use student-centered evaluation techniques. This general belief, however, is not always confirmed and supported by the data, in fact within the research sample there are just over half those who do not use alternative evaluation tools and techniques or do so only partially, and a third those who do not use methods of student-centered evaluation. It is seen that lecturers are aware of the possible benefits of alternative assessment and evaluation practices, but they seem to encounter difficulties in their practical application for design, methodological and technological reasons.

The difficulties identified at design level are referred to the complexity of the construction of an authentic and/or performance-based task. Specifically, they concern the characteristics of the task to be assigned, which must be executable online, the selection of online materials and sources, the assignment of roles if the task involves cooperative groups, the management of online interactions between peers and between students and lecturers, modalities for communicating feedback (chat, forum, messaging systems, interactive platforms, etc.), methods of carrying out the task in sequential or parallel, synchronous or asynchronous mode, the time allocated for carrying out the task and to present the final product. Compared to the preparation of traditional tests (open-ended answer, multiple choice answer, true or false tests, etc.), an authentic and/or performancebased task requires a much more detailed and articulated design [34]. Furthermore this implies that lecturers have knowledge and experience on how they can use alternative assessment and evaluation techniques in distance education. Also the management of cheating, which seems to be one of the main concerns of lecturers even in distance evaluation, is much more difficult to keep under control while carrying out an authentic task, a project, a search path, while it can be done more easily for tests. On the other hand, authentic tasks can be a strategy to overcome test cheating, because in this case the purpose of the task is not to answer correctly by selecting the right option, but to have original, creative, personal and contextualized products to evaluate [35]. Even the lecturers of this research sample stated that one of the main strengths of the alternative assessment and evaluation practices is not aiming at memorizing information, but rather enabling students to use high-order thinking skills and prevent them from cheating [36].

If the design of an alternative assessment tool is not easy, the evaluation of the learning products that derive from it is equally demanding and it poses relevant docimological questions to the lecturers. The final evaluation of an authentic task, a group project, a report, a case study puts the evaluator in front of a plurality of possible answers, rather than predefined unique answers, that must be analysed. To verify the quality with which the task was carried out, many aspects have to be considered, such as: the understanding and setting the problem, use of information and sources, logical connection between between hypotheses and results, internal consistency of the resolution process, correctness of results, sustainability and feasibility of advanced solutions [37-38]. All 
these aspects have to do with the definition of valid and reliable evaluation criteria, capable of accurately evaluating student performance. As confirmed in the replies to the questionnaire, lecturers indicate that preparing and evaluating alternative tools take a lot of time and effort, for this reason they are more inclined to use tests for online exam practices even though they find traditional exams inadequate in evaluating success and performance. Other studies also come to the same conclusions [39-40], in fact, they underline that while the workload that traditional evaluation brings on lecturers is stable, online evaluation has a fluctuated trend dependent on the complexity and nature of the task.

The technological implications of using online alternative assessment and evaluation are obvious. It needs to be supported by good connectivity systems and performing elearning platforms, equipped with adequate plug-ins that go beyond the structured tests. The lecturers themselves must be adequately competent in the use of ICT for managing the processes and alternative assessment tools. In many cases, lecturers claim that they do not use alternative assessment tools and practices not so much because they do not believe in their effectiveness, but because they do not know how to propose significant authentic tasks to students to do online [41-42]. For this reason, the same lecturers use alternative assessment methods in face-to-face education, but not in online education. When the lecturers do not have a consolidated technological competence or are unable to promptly address the technical problems that may occur during the online assessment, the evaluation results themselves can be compromised and made less reliable [43].

The above critical issues highlight the importance of alternative assessment tools and techniques for the evaluation of competences in distance higher education, but also the need for the evaluation research to continue to work in order to develop methodologies aimed at increasing the validity and reliability of alternative evaluation methods. The increasingly widespread and conscious use of alternative assessment tools can have positive implications for both students and organizations that provide distance education.

In the first case, the use of alternative assessment and evaluation practices not only favours the social construction of knowledge by creating social constructivist learning environments and improving communication interaction in distance education, but allows the students themselves to constantly monitor both the quality of their learning outcomes and the learning process that determines them [44]. As some authors argue [45-50], alternative assessment and evaluation help students to become more competent acquiring basic, transversal and technical competences - and allow students themselves to understand how their performance can be improved and made adaptable to a plurality of changing contexts. This ability to reflect on the feedback resulting from one's actions, as D. A. Schön [51] says, does not happen only after the action ("reflection-on-action"), but occurs in the course of the action ("reflection-in-action"), while students' or practitioners' competence is being formed through action, producing a higher level of awareness and proficiency.

In the second case, it is important that distance education organizations detect the effective impact of alternative assessment and evaluation methods on their training offer, starting with questions like: "How much are they known and used by the lecturers?", "What is the degree of familiarity that the students have with these practices?". Studies that have investigated the impact of alternative and authentic assessment on online higher education show not only an increase in the quality of students' knowledge and skills, attested by a higher rate of success in final exams, but also an increase in student satisfaction towards online activities [52-53]. Other research demonstrate how the use of alternative assessment tools and techniques is greater in cases where these are used not only in the final exams, thus responding to a summative function of the evaluation, but also in itinere, during the implementation of courses or education programs, thus 
enhancing the formative function of alternative assessment [54-55]. For this purpose tools such as authentic tasks, portfolios, research projects, simulations, experiments, laboratory experiences, production of artefacts, etc. turn out to be the ones preferred by lecturers. In some cases [56], the usefulness of a complementary use of traditional evaluation methods and tools with alternative ones was also noted for both formative and summative evaluation activities.

According to the data emerged from the present research, it can be stated that the use of alternative assessment methods is useful not only in emergency contexts, such as those caused by the Covid-19 pandemic, but in any context of distance learning and evaluation. The state of emergency of the pandemic has contributed to a better understanding of the strengths and weaknesses of alternative assessment and evaluation in distance learning, not to be considered exclusively but to be used together with other approaches. Indeed, an integration between alternative assessment and traditional assessment can maximize the advantages of both methods, making competence assessment more sustainable even beyond the pandemic [57-58].

\section{References}

1. F. M. Reimers, A. Schleicher, A framework to guide an education response to COVID-19 Pandemic of 2020, (OECD, 2020)

2. R. Lake, L. Olson, Learning as We Go: Principles for Effective Assessment during the COVID19 Pandemic (Center on Reinventing Public Education, 2020)

3. M. Scriven, The methodology of evaluation. In R. W. Tyler, R. M. Gagné, \& M. Scriven (Eds.), Perspectives of curriculum evaluation, (Rand McNally, Chicago. IL, 1967)

4. E. Hargreaves, Assessment. In G. McCulloch, \& D. Crook (Eds.), The Routledge international encyclopaedia of education, (Routledge, New York, 2008)

5. N. Pachler, C. Daly, Y. Mor, H. Mellar, Computers \& Education, 54, 715, (2020)

6. Z. Chen, Z., J. Jiao, J., K. Hu, IJDET, 19, 1, 1, (2021)

7. E. Maclellan, Assessment \& Evaluation in Higher Education, 29, 3, 311, (2004)

8. J. L. Herman, A practical guide to alternative assessment, (Association for Supervision and Curriculum Development, Pitt Street, Alexandria, 1992)

9. C. T. McKevitt, Journal of University Teaching \& Learning Practice, 13, 1, 2, (2016)

10. C. Janisch, X. Liu, A. Akrofi, The Educational Forum, 71, 3, 221, (2007)

11. L. A. Shepard, Educational Researcher, 29, 7, 4, (2000)

12. T. C. Reeves, J. R Okey, in Constructivist learning environments Case studies in instructional design, (Educational Technology Publication. New Jersey, 1996)

13. Z. Libman, Studies in Educational Evaluation, 36, 1-2, 63, (2010)

14. S. Hase, C. Kenyon, Complicity: An international journal of complexity and education, 4, 1, $111,(2007)$

15. E. Oliver, E, HTS Theological Studies, 71, 3, 1, (2015)

16. D. R. Garrison, N. D. Vaughan, Blended learning in higher education: Framework, principles, and guidelines (John Wiley \& Sons, San Francisco, 2008)

17. M. J. Koehler, P. Mishra, K. Kereluik, T. S. Shin, C. R. Graham, in Handbook of research on educational communications and technology, 101-111 (Springer, New York, NY, 2014)

18. J. W. Creswell, V. L. P. Clark, Designing and conducting mixed methods research (Sage, Thousand Oaks, 2017)

19. J. W. Creswell, J. D. Creswell, Research design: Qualitative, quantitative, and mixed methods approaches (Sage, Thousand Oaks, 2017)

20. R. Yilmaz, Turkish Online Journal of Distance Education, 18, 1, 39, (2017)

21. T. C. Reeves, Journal of Educational Computing Research, 23, 1, 101, (2000)

22. T. Kellaghan, D. L. Stufflebeam (Eds.), International Handbook of Educational Evaluation: Part One: Perspectives/Part Two: Practice, (Springer Science \& Business Media, 2012)

23. E. Maclellan, Assessment \& Evaluation in Higher Education, 29, 3, 311, (2004)

24. S. Friese, Qualitative data analysis with ATLAS. ti., (Sage, Thousand Oaks, 2019) 
25. SIRD (Italian Society for Educational Rsearch) (Ed.), La DaD in emergenza: vissuti e valutazioni degli insegnanti italiani. Scelte metodologiche e primi risultati nazionali, (Pensa Multimedia, Lecce, 2021)

26. Z. Libman, Studies in Educational Evaluation, 36, 1-2, 62, (2010)

27. N. Nasri, S. N. Roslan, M. I. Sekuan, K. A Bakar, S. N. Puteh, Procedia-Social and behavioral sciences, 7, 37, (2010)

28. J. Herrington, T. C. Reeves, R. Oliver, Distance Education, 27, 2, 233, (2006)

29. T. Amiel, J. Herrington, in Informed design of educational technologies in higher education: Enhanced learning and teaching, (IGI Global, Hershey, PA, USA, 2012)

30. D. Lawton, N. Vye, J. Bransford, E. Sanders, M. Richey, D. French, R. Stephens, Journal of Engineering Education, 101, 2, 244, (2012)

31. J. Gaytan, B. C. McEwen, The American Journal of Distance Education, 21, 3, 117, (2007)

32. C. Rapanta, L. Botturi, P. Goodyear, L. Guàrdia, M. Koole, Postdigital Science and Education, 2, 3, 923, (2020)

33. S. Mathur, T. Murray, in Online assessment, measurement and evaluation: Emerging practices, (IGI Global, Hershey, PA, USA, 2006)

34. M. Bearman, P. Dawson, D. Boud, S. Bennett, M. Hall, E. Molloy, Teaching in Higher Education, 21, 5, 545, (2016)

35. A. Munoz, J. Mackay, Journal of University Teaching \& Learning Practice, 16, 3, (2019)

36. G. Watson, J. Sottile, J. G. Liang, Journal of Research in Education, 24, 1, 120, (2014).

37. P. Williams, Teaching in Higher Education, 19, 5, 565, (2014)

38. E. Gozuyesil, I. Tanriseven, Eurasian Journal of Educational Research, 17, 70, 37, (2017)

39. R. Benson, C. Brack, Online learning and assessment in higher education: A planning guide, (Chandos Publishing, Oxford, 2010)

40. R. L. Chang, K. Gray, Journal of Computing in Higher Education, 25, 3, 147, (2013)

41. D. Jonassen, J. Howland, R. M. Marra, D. Crismond, Meaningful Learning with Technology (Pearson Education Inc., New Jersey, 2009)

42. B. C. Litchfield, J. V. Dempsey, New Directions for Teaching and Learning, 142, 142, 65, (2015)

43. S. Bennett, P. Dawson, M. Bearman, E. Molloy, D. Boud, British Journal of Educational Technology, 48, 2, 672, (2017)

44. Z. Libman, Studies in Educational Evaluation, 36, 1-2, 62, (2010)

45. J. Gaytan, B. C. McEwen, The American Journal ofDistanceEducation, 21, 3, 117, (2007)

46. S. Vonderwell, X. Liang, K. Alderman, Journal of Research on Technology in Education, 39, 3, 309, (2007)

47. D. A. Schön, Change: The Magazine of Higher Learning, 27, 6, 27, (1995)

48. R. Benson, C. Brack, Online learning and assessment in higher education: A planning guide, (Chandos Publishing, Oxford, 2010)

49. L. Dunn, C. Morgan, M. O'Reilly, S. Parry, The student assessment handbook: New directions in traditional and online assessment, (Routledge, London, 2003)

50. J. W. Gikandi, D. Morrow, N. E. Davis, Computers \& Education, 57, 4, 2333, (2011)

51. J. Mateo, A. Sangrà, European Journal of open, distance and E-learning, 10, 2, (2007)

52. D. J. Nicol, D. Macfarlane-Dick, Studies in higher education, 31, 2, 199, (2006)

53. M. Birenbaum, K. Breuer, E. Cascallar, F. Dochy, Y. Dori, J. Ridgway, G. Nickmans, Educational Research Review, 1, 1, 61, (2006)

54. J. W. Looney, Integrating Formative and Summative Assessment: Progress Toward a Seamless System? (OECD Education Working Papers, No. 58, OECD Publishing, 2011) 